\title{
Prevalence of optic disc haemorrhages in an elderly UK Caucasian population and possible association with reticular pseudodrusen- the Bridlington Eye Assessment Project (BEAP): a cross-sectional study (2002-2006)
}

\author{
Craig Wilde ${ }^{1} \cdot$ Ali Poostchi $\mathbb{I}^{1} \cdot$ Rajesh Narendran $^{2} \cdot$ Hamish K. MacNab ${ }^{3} \cdot$ Jonathan G. Hillman $^{3} \cdot$ \\ Phillip Alexander $\mathbb{D}^{4} \cdot$ Winfried M. Amoaku $\mathbb{D}^{1} \cdot$ Stephen A. Vernon ${ }^{5}$
}

Received: 17 December 2017 / Revised: 26 June 2018 / Accepted: 27 August 2018 / Published online: 1 November 2018

(c) The Royal College of Ophthalmologists 2018

\begin{abstract}
Aims To determine disc haemorrhage (DH) prevalence in an elderly UK population-the Bridlington Eye Assessment Project (BEAP).

Methods Thirty-degree fundus photographs (3549 participants $\geq 65$ years) were graded for DH/macula changes. Glaucoma evaluation included Goldmann tonometry, 26-point suprathreshold visual-fields and mydriatic slit-lamp assessment for glaucomatous optic neuropathy.

Results In all, 3548 participants with photographs in at least one eye. DHs were present in 53 subjects (1.49\%), increasing from $1.17 \%$ (65- to 69-year age group) to $2.19 \%$ (80- to 84-year age group), $p=0.06$. DH was found in 9/96 (9.38\%) right eyes (RE) with open-angle glaucoma (OAG). Two of twelve RE (16.67\%) with normal-tension glaucoma (NTG) had DH. Prevalence in eyes without glaucoma was lower (32/3452, [0.93\%]). Reticular pseudodrusen (RPD) occurred in 170/3212 (5.29\%) subjects without DH, and 8/131 subjects (6.11\%) with OAG. Twenty eyes had NTG, two of whom had RPD (10\%) $(p=0.264)$. Within a logistic regression model, DH was associated with glaucoma (OR 10.2, 95\% CI 5.32-19.72) and increasing age (OR 1.05, 95\% CI 1.00-1.10, $p=0.03)$. DH was associated with RPD $(p=0.05)$ with univariate analysis but this was not statistically significant in the final adjusted model. There was no significant association with gender, diabetes mellitus (DM), hypertension treatment or Age-related Macular Degeneration (AMD) grade.

Conclusion DH prevalence is $1.5 \%$ in those over 65 years old and significantly associated with glaucoma and increasing age. There appears to be increased RPD prevalence in eyes with DH and NTG with age acting as a confounding factor. Larger studies are required to fully assess the relationship and investigate a possible shared aetiology of choroidal ischaemia.
\end{abstract}

Stephen A. Vernon

profsavernon@doctors.org.uk

1 Ophthalmology and Vision Sciences, Division of Clinical Neurosciences, B Floor, EENT Centre, Queen's Medical Centre, University of Nottingham, Nottingham, UK

2 Department of Ophthalmology, Scarborough Hospital, York Teaching Hospital NHS Foundation Trust, York, UK

3 The Medical Centre, Station Avenue, Bridlington YO16 4LZ, UK

4 Department of Vitreoretinal Surgery, Cambridge University Hospitals, Cambridge, UK

5 BMI Park Hospital, Nottingham, UK

\section{Introduction}

Optic disc haemorrhages (DHs) in association with glaucoma are characteristically flame or splinter shaped, occurring at the border of, or involving the optic nerve head. Originally reported by Bjerrum [1], the term 'glaucoma haemorrhagicum' was used to describe patients with glaucoma and DH. They are considered a hallmark for glaucomatous optic neuropathy [2-9]. Approximately 100 years later, Drance and Begg [10] recognised the association between $\mathrm{DH}$ and glaucoma progression after noting a patient with 'chronic simple glaucoma' and asymptomatic DH developed a new corresponding visual field (VF) defect with subsequent neuroretinal rim focal thinning. Drance et al. [2] later published their finding that $71 \%$ of primary 
open-angle glaucoma (POAG) patients with evidence of DH developed progressive VF defects, compared to $33 \%$ of those without. They reported that among patients with ocular hypertension, $34 \%$ with a visible DH developed VF defects, compared to $3 \%$ of those without [2].

Several population-based studies have published the prevalence of DHs, demonstrating they are infrequently found in normal eyes $(0.9-3.4 \%)$ [4, 11-15]. They have their highest prevalence $(11-46 \%)$ in eyes with normaltension glaucoma (NTG) [13, 16-18], with lower prevalence among eyes with POAG (2-37\%) and OHT (0.4$10 \%)[13,14,17]$. There are reports DHs are more common in women, with increasing age and vascular disease [13]. Other associations include diabetes mellitus (DM) [13, 19], migraine [13], pseudoexfoliation [13], aspirin use [19] and systemic hypertension [13, 20]. Jonas et al. reported disc morphology associations. Among POAG patients, those with small neuroretinal rims and large peripapillary beta zone changes were more likely to develop DH [21]. Hospital-based prevalence studies however have the disadvantage of selection bias. In the United Kingdom no population-based study has measured DH prevalence.

The purpose of the present study is to report DH prevalence in an elderly UK population, among those with and without glaucoma and investigate associations with systemic and ocular parameters.

\section{Methods}

\section{Study design}

The Bridlington Eye Assessment Project (BEAP) study methodology, including image acquisition and analysis is described elsewhere [22]. Briefly, the BEAP is a singlecentre population-based prevalence study, designed to investigate the utility of screening for eye disease in an elderly population $\geq 65$ years, using clinical examination by optometrists and digital imaging technology. Primary ophthalmic diseases studied were AMD, cataract and glaucoma. Bridlington is a coastal town in Yorkshire, UK, with a stable, predominantly Caucasian population. The study received approval from the local ethics committee (Scarborough and North East Yorkshire Local Ethics Research Committee; Ref No. PB/RH/02/288). Its methodology adhered to the tenets of the Declaration of Helsinki. Study recruitment occurred between 5 November 2002 and 29 March 2006. All participants were interviewed, in person, by a trained research nurse using a structured questionnaire, and examined by one of four specially trained optometrists with a pro-forma completed by research staff. Nonstereoscopic mydriatic fundus photography was performed with a Topcon fundus camera (model TRC NW6S) and
Nikon 10-megapixel camera. Each eye had a $30^{\circ}$ colour fundus photograph (CFP) taken, centred on the macula. In total, 3549 individuals attended the initial study examination (56\% of the eligible population). Basic demographic information was available for all subjects within the sampling frame. Gender balance was similar for both attenders and non-attenders.

Two ophthalmologists (CW and RN) independently examined each photograph for the presence of DH. All CFPs were separately graded for other ocular pathologies, including AMD and reticular pseudodrusen (RPD) by one examiner $(\mathrm{CW})$ using definitions and grids as described in the International Classification System for AMD and as reported elsewhere [22].

Grading was masked, in the absence of all demographic data, and results of ocular examinations, tests or final diagnoses. Each eye was graded separately. The final grade assigned to each participant was that of either eye.

DHs were defined as haemorrhages lying completely inside the optic nerve head, those extending beyond or those touching the optic disc border. Examples are shown in Figs. 1 and 2. Haemorrhages located completely outside the optic disc head were excluded, as they may be secondary to other ocular diseases. Eyes with visible diabetic retinopathy, retinal vein occlusions or collateral disc vessels and optic disc oedema, or eyes with signs of other ocular pathology, such as peripapillary choroidal neovascular membranes, were excluded from analysis. In eyes with DH the number, locations and shapes were recorded.

All photographs showing DH were reviewed by a glaucoma subspecialist (SAV) who acted as final arbiter.

Within the BEAP all subjects were assessed for glaucoma. Intraocular pressure (IOP) was measured using a

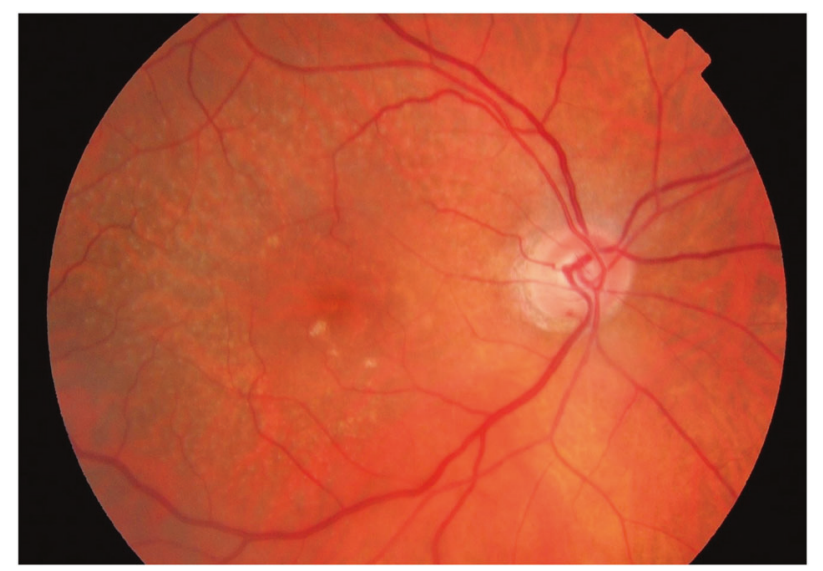

Fig. 1 Colour fundus photograph of right eye showing extensive dot and ribbon RPD. There is an inferior DH with associated thinning of the neuroretinal rim and a focal notch. There is temporal bayoneting at the optic disc edge. There is a tessellated appearance to the fundus with decreased pigmentation inferior to the optic disc and peripapillary pigmentary changes. There are sparsely visible choroidal vessels between the optic disc and macula 


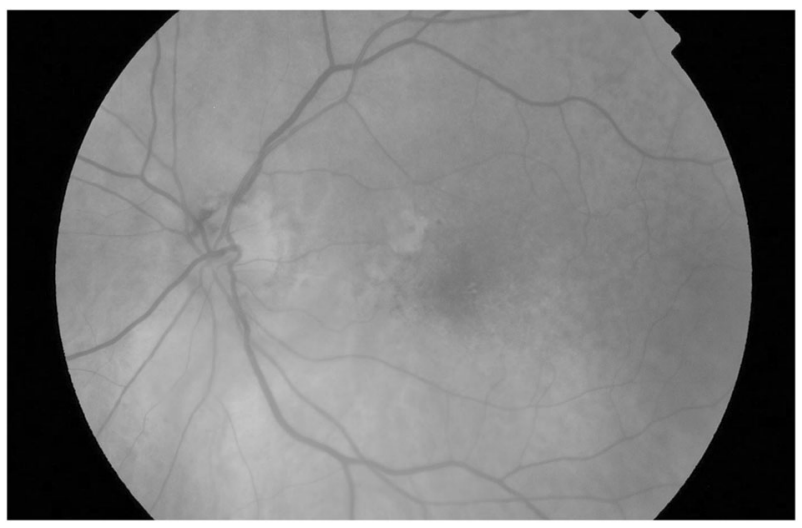

Fig. 2 Superonasal neuroretinal rim DH associated with co-morbid geographic atrophy and temporal ribbon RPD. There are some photographic features of age-related choroidal atrophy, including peripapillary atrophy and pigmentary changes. There is a large area of inferior scleral show

calibrated Goldmann applanation tonometer. VF testing using a Henson Pro 5000 automated perimeter, software v3.1.4 (Tinsley Instruments, Croydon, UK) with singlestimulus, suprathreshold, central 26-point strategy was employed. The test was automatically extended to 68 points if defects were detected. The perimeter automatically graded outputs as normal, suspect or defect. For study purposes, any defect including those classified as suspicious were treated as abnormal. Estimation of vertical cup to disc ratio was performed using a $90 \mathrm{D}$ condensing lens by the examining optometrist, who recorded the presence of pathological features, including $\mathrm{DH}$, bayonetting and focal notching, before deciding if the disc appeared abnormal using criteria developed by Jonas et al. [23, 24]. Subjects with abnormal VFs, raised IOP $(\geq 21 \mathrm{~mm} \mathrm{Hg})$ or disc features suspicious for glaucoma were referred to the hospital eye service for assessment by one of four consultant ophthalmologists. A definitive clinical diagnosis of glaucoma would be assigned following clinic assessment or appropriate follow-up. All glaucoma diagnoses were reviewed by a single glaucoma subspecialist (SAV) using a minimum of 5 years longtitudinal data to confirm incident disease at referral.

\section{Statistical methods}

All data were analysed with Stata v14 (Stata Corp, College Station, Tx, USA). Associations between groups were explored using unpaired $t$-tests for continuous variables and chi-squared test for discrete variables. Where necessary, results were stratified using Mantal Haenzel methods. Logistic regression was used for multivariate analysis and to determine odd ratios in the final adjusted model and was computed using a stepwise approach with each relevant additional variable added sequentially and the model rechecked for change.

\section{Results}

In total, 3548 Caucasian participants had gradable photographs of the optic nerve in at least one eye, with 3255 having gradable CFP in both. DHs were present in 53 subjects ( $1.49 \%$ prevalence for either eye), in the $\geq 65$-year age group. A total of 25 subjects with DH were female (47.2\%). Males had a higher gender-specific prevalence $(1.79 \%$ vs $1.26 \%)(p=0.19)$; on multivariate logistical regression analysis this difference was not statistically significant (odds ratio (OR) female gender 0.65 , confidence interval (CI) $0.37-1.14)$. DH frequency for right $(n=41,77.4 \%)$ and left eyes $(n=12,22.6 \%)$ appeared to be different. Mean age for subjects with DH was 77.01 years (SD 7.55 [Table 1]) and DH prevalence demonstrated a trend to increase with age from $1.17 \%$ in the 65 - to 69 -year age group, to a maximum of $2.19 \%$ in the 80 - to 84 -year age group $(p=0.06)$.

For right eyes, 32 out of $41(78.0 \%)$ DHs occurred in eyes without a definite diagnosis of OAG.

In total, 96 of 3548 right eyes (2.7\%) had open-angle glaucoma (OAG). Of all 41 right eyes with $\mathrm{DH}, 9$ had definite OAG (22\%), representing 9 out of $96(9.38 \%)$ DH right eyes with definite OAG. Twelve right eyes were identified with NTG, of which 2 had DH (16.67\%). The prevalence of DH in non-glaucomatous eyes was $0.93 \%$ ( 32 of 3452 eyes). In a univariate analysis, presence of DH was significantly $(p<0.05)$ associated with older age and NTG.

RPD occurred in 170 of 3212 (5.29\%) subjects with no $\mathrm{DH}$, and in 8 of 131 subjects $(6.11 \%)$ with OAG. Twenty eyes had NTG, 2 of which had RPD (10\%) $(p=0.264)$. In univariate analysis, DHs were significantly associated with the presence of RPD $(p=0.048)$. Among the 3264 subjects with gradable images (for both RPD and DH), 6 of 52 eyes (11.54\%) with DH had RPD. Five of 53 eyes (9.43\%) with DH had either geographic atrophy or neovascular AMD in their worse eye.

Within a logistic regression model, we found that DH was associated with glaucoma (OR 10.2, 95\% CI 5.32-19.72) and increasing age (OR 1.05, 95\% CI 1.00$1.10, p=0.03$ ) corresponding to annual $5 \%$ increase in risk. DH was associated with RPD $(p=0.05)$ in the univariate analysis but this was not significant in the final adjusted model. There was a weak association between RPD and DH $(p=0.05)$, which was not significant when we corrected for age (OR 1.87, CI $0.74-4.74, p=0.18)$. There was no significant association between DH and gender, DM, hypertension treatment or AMD grade. 
Table 1 The characteristics of patients with and without disc haemorrhages (DHs)

\begin{tabular}{|c|c|c|c|c|}
\hline Variable & With DH & Without DH & Total & $p$-Value \\
\hline $\begin{array}{l}\text { Mean age [years] (95\% confidence } \\
\text { interval) }\end{array}$ & $\begin{array}{l}77.01 \\
(74.93-79.09)\end{array}$ & $\begin{array}{l}75.04 \\
(74.84-75.23)\end{array}$ & $\begin{array}{l}75.07 \\
(74.87-75.26)\end{array}$ & $0.016^{\mathrm{a}}$ \\
\hline \multicolumn{5}{|l|}{ Gender } \\
\hline Male & $28(1.80)$ & $1530(98.20)$ & 1558 & \multirow[t]{2}{*}{$0.195^{\mathrm{b}}$} \\
\hline Female & $25(1.26)$ & $1953(98.74)$ & 1978 & \\
\hline \multicolumn{5}{|l|}{ Diabetes mellitus } \\
\hline Yes & $3(0.85)$ & $352(99.15)$ & 355 & \multirow[t]{2}{*}{$0.283^{\mathrm{b}}$} \\
\hline No & $50(1.58)$ & $3121(98.42)$ & 3171 & \\
\hline \multicolumn{5}{|l|}{ Hypertension treatment } \\
\hline Yes & $27(1.60)$ & $1662(98.40)$ & 1689 & \multirow[t]{2}{*}{$0.701^{\mathrm{b}}$} \\
\hline No & $26(1.44)$ & $1780(98.56)$ & 1806 & \\
\hline \multicolumn{5}{|c|}{ Patients with no AMD in worse eye (Rotterdam grade 0 ) } \\
\hline Yes (grade 0) & $20(1.5)$ & $1317(98.50)$ & 1337 & \multirow[t]{2}{*}{$0.991^{b}$} \\
\hline No (grade 1-4) & $33(1.50)$ & $2166(98.50)$ & 2199 & \\
\hline
\end{tabular}

\section{Discussion}

Despite their importance and association with glaucoma, no UK population-based report of DH prevalence exists, with a paucity of studies from European Caucasian populations. Many reports are hospital-based focusing on subjects with an established glaucoma diagnosis, ocular hypertension or documented $\mathrm{DH}$, with associated selection bias $[3,4,13$, $25,26]$. The prevalence of DH in the Bridlington (UK) population (aged $>65$ years) of $1.5 \%$ is comparable to that in other large population-based studies, including $1.2 \%$ in Japan [14], Australia (1.4\%) [13], United States (0.9\%) [11] and China (1.2\%) [12]. To date our finding represents the highest population-based prevalence, which may reflect the older age of our cohort.

In this study, DH was significantly associated with age, with prevalence reaching $2.19 \%$ in the 80 - to 84 -year age group. This is consistent with previous population [12] and hospital-based studies [21, 27]. Jonas et al. reported an OR of 1.48 for 10 -year increase in age for $\mathrm{DH}$ development [21]. In the Ocular Hypertension Treatment Study, patients with DH were older than those without (59.0 vs 55.2 years, $p<0.01$ ) [27]. Our finding of a 1.05 increased risk of DH per year is similar to that in the Korean National Health and Nutritional Examination Survey (1.04-fold increased risk per year) [28].

Previous studies have reported conflicting results relating to the association between DH and gender. In this study, DH prevalence was higher in men but the difference was not statistically significant (OR female gender 0.65 , CI $0.37-1.14)$. This is in line with population-based studies from South Korea [29] and China [12]. In the Blue
Mountains Eye Study (BMES), DH prevalence was higher in woman (OR 1.9, CI 1.0-3.5) [13], after adjustment for age and glaucoma, while a female preponderance has also been reported elsewhere [11, 30, 31].

This study confirms most DH occur in healthy individuals with no (current) diagnosis of glaucoma, while only $27 \%$ of DH occur in glaucomatous eyes (OAG or NTG), reflecting the relative rarity of OAG. This finding is higher than in the Beijing Eye Study (where 20\% of DH was detected in glaucomatous eyes) [12].

Glaucoma remains the most important disease associated with DH and the reported prevalence among glaucoma patients varies considerably, ranging from 4.2 to $17.6 \%$ for POAG and 19.4 to $35.3 \%$ for NTG [13, 16, 32-34]. In our study DH prevalence in subjects with OAG was $9.4 \%$, being similar to other population-based reports, including $13.8 \%$ in the BMES, $8.8 \%$ in the Beijing Eye Study and $8.2 \%$ in the Tajimi study [31]. Our findings of higher DH prevalence among eyes with NTG $(16.7 \%)$ is in keeping with previously published reports [13].

The positive predictive value (PPV) of $\mathrm{DH}$ varies throughout the literature, appearing to reflect the type of glaucoma most prevalent within the population. In a Japanese study, where NTG is most prevalent, the PPV was high $(52.9 \%)$ [14]. Of clinical relevance is the finding that a DH in our UK population has a PPV of $27 \%$ for OAG or NTG, as $27 \%$ of right eye DHs was found in eyes with OAG or NTG. This is similar to findings from other studies within predominantly Caucasian populations of European ancestry [13].

The putative finding of higher DH frequency for right eyes $(n=41,77.4 \%$ vs $n=12,22.6 \%)$ was unexpected, likely reflecting a chance finding. Laterality of DH is often 
not reported or discussed. The unit of study is often either eye. In the BMES [13], DH prevalence was highest for left eyes $(34 / 56,60.7 \%$ vs $22 / 56,39.3 \%)$. Siegner et al. [8] in a hospital-based population reported DHs were identified in $51 \%$ of right eyes. It has been demonstrated that low diastolic perfusion pressure is an independent risk factor for development of OAG [35], with suggestions that lower ocular perfusion pressure results in reduced ocular blood supply, resulting in glaucomatous optic neuropathy. Differences in systolic BP between arms can predict increased risk of cardiovascular events and all-cause mortality over a 10-year period in people with hypertension [36]. Some studies have suggested that diastolic BP is, on average, lower in the right arm and may be related to differing pulse pressures along the aorta [36-38]. However, the literature is inconsistent and inconclusive.

The pathogenesis of DH has not been fully elucidated. We report a newly described ocular association between DH and RPD, which may offer further insight into DH aetiology. We draw comparisons between demographic and pathological similarities among subjects with RPD, DH and NTG, and propose they may share an aetiological connection through choroidal ischaemia.

Within the BEAP, RPD are more common than recognised in prior population-based studies, with a prevalence of $5 \%$ in persons aged $>65$ years. Like NTG, RPD are consistently more prevalent in females. Their prevalence, like NTG, increases significantly with age, reaching a maximum of $27 \%$ in persons aged $>90$ years [22]. In the current study RPD prevalence is increased in individuals with NTG (11.5\%) when compared to the population as a whole $(5 \%)$, or when compared to all subjects with OAG $(6.11 \%)$; in a univariate model, DHs were associated with RPD ( $p=$ 0.048), although this association was lost in multivariate analysis. Given the relative rarity of DH and RPD, and small numbers involved (with age acting as a confounding factor), a larger sample size may be required to confirm or refute any genuine association.

Arnold et al. [39] speculated that RPD result from poor choroidal perfusion after describing fibrosis within choroidal stroma between large choroidal veins. While choroidal thinning is consistently found in eyes with RPD [40, 41], juxtapapillary choroidal thinning has been documented in eyes with NTG [42-44]. Others have demonstrated reduced blood flow in the peripapillary retina in NTG eyes [45, 46], suggesting blood flow deficits may accompany or contribute to NTG. RPD may form part of a spectrum of chorioretinal changes seen in age-related choroidal atrophy, in which peripapillary atrophy (PPA), tessellation of the fundus, choroidal thinning and glaucoma are described associations [47]. There is increasing evidence of an association between RPD and cardiovascular disease and risk factors, including hypertension [48] and angina [49]. A recent publication demonstrated an association with diffuse-trickling Geographic Atrophy (GA) (which is strongly associated with RPD) and cardiovascular disease, particularly in males [50], and in the $<65$-year age group, $54 \%$ of patients had previously been admitted to hospital with cardiovascular disease, including hypertensive crisis, angina and myocardial infarction [50]. Similar associations between vascular insufficiency and NTG have been raised. Migraines are associated with transient vasospastic episodes that can result in impaired cerebral blood flow and have been consistently associated with NTG [51, 52] and progression of NTG [53]. In the Low-Pressure Glaucoma Treatment Study a history of migraine, low systolic blood pressure and use of systemic $\beta$ blockers were associated with DH [54]. Hypertension, like RPD, has also been associated with DH in NTG [20].

PPA is another known feature shared among subjects with NTG (often with cupping most pronounced in areas of RPE loss) [55], DH [56] and RPD [57], offering further biological plausibility into a shared common pathway. Interestingly, flame-shaped DH occur most frequently in a superotemporal location [13]. Similarly, RPD have increased prevalence within the superotemporal macula [58]. We hypothesise that RPD, DH and NTG, in some instances, may be manifestations of the same aetiological pathway of choroidal ischaemia. We highlight the short posterior ciliary arteries (SPCA) supply both the choroid and prelaminar portion of the optic nerve head, along with the peripapillary choroid. We hypothesise chronic ischaemia via the SPCA may result in a spectrum of overlapping changes including DH, PPA, RPD and NTG in some individuals. Large prospective studies in NTG patients are required to investigate this association further. Utilisation of multimodal imaging for the optic disc, peripapillary area and macula choroid, with perfusion studies would be invaluable.

The possible association of RPD and NTG is important. The Beaver Dam Eye Study reported not only an association between RPD and glaucoma, but the highest 15-year incidence of AMD among subjects with RPD (43\% and $46 \%$ in right and left eyes, respectively) [58]. This was twice the risk when compared to subjects with soft indistinct drusen. If RPD, DH and NTG are associated through shared aetiological mechanisms, patients with NTG will need appropriate macula imaging in clinics, advice regarding risk of AMD with provision of lifestyle advice and amsler grid for home screening. Similarly, clinicians should have a high index of suspicion while reviewing patients with RPD, paying attention to optic disc morphology for features of NTG, being aware of potential difficulties in diagnosing NTG in patients with AMD. Moreover, there is evidence suggesting patients with AMD and glaucoma pose extra hazards such as increased difficulties walking safely when compared to patients with glaucoma alone [59]. This 
is not surprising when glaucoma predominantly affects tasks requiring contrast discrimination and peripheral vision/light-dark adaptation [60], while AMD influences tasks involving central vision such as reading and recognising faces [61].

Limitations of this study include its purely Caucasian participants, which could limit generalisability to the wider UK population. Optic disc and macula imaging was limited to non-stereoscopic CFPs. Multimodal imaging would have been preferred for both, particularly for detecting RPD. Prospective follow-up would have been preferred. While we have corrected for the majority of important co-variants, there are known associations that were not specifically questioned such as a history of Raynaud's phenomenon, migraines and use of $\beta$ blockers or anticoagulants.

\section{Summary}

\section{What was known before}

- DHs are an infrequent finding in normal eyes but are common in eyes with NTG.

- DHs are associated with increasing age, vascular disease and female gender.

\section{What this study adds}

- This is the first UK population-based study to report prevalence of DH.

- This is the first study to report a possible increased prevalence of RPD in eyes with DH and NTG, suggesting a possible shared aetiology of choroidal ischaemia, but further larger studies are required to confirm these findings.

Acknowledgements This research was funded in part by a Research Grant from the Macular Society UK, Andover, Hants and an unrestricted grant from Guide Dogs for the Blind, Reading, Berkshire, UK. The Bridlington Eye Assessment Project was funded by an unrestricted grant from Pfizer. We would also like to thank the following organisations for financial support of the Project: Pharmacia, Yorkshire Wolds and Coast Primary Care Trust, The Lords Feoffees of Bridlington, Bridlington Hospital League of Friends, The Hull and East Riding Charitable Trust, The National Eye Research Centre (Yorkshire), The Rotary Club of Bridlington, The Alexander Pigott Wernher Memorial Trust, Bridlington Lions Club, The Inner Wheel Club of Bridlington, Soroptimist International of Bridlington and The Patricia and Donald Shepherd Charitable Trust.

\section{Compliance with ethical standards}

Conflict of interest The authors declare that they have no conflict of interest.

\section{References}

1. Bjerrum J. Om en tilfojeke til den saedvanlige synsfelfundersogelse samt om synfelet ved glaukom. Nord Ophthalmol Tskr. 1889;2:141-85.

2. Drance SM, Fairclough M, Butler DM, Kottler MS. The importance of disc hemorrhage in the prognosis of chronic open angle glaucoma. Arch Ophthalmol. 1977;95:226-8.

3. Airaksinen PJ, Mustonen E, Alanko HI. Optic disc hemorrhages. Analysis of stereophotographs and clinical data of 112 patients. Arch Ophthalmol. 1981;99:1795-801.

4. Bengtsson B, Holmin C, Krakau CE. Disc haemorrhage and glaucoma. Acta Ophthalmol. 1981;59:1-14.

5. Heijl A. Frequent disc photography and computerized perimetry in eyes with optic disc haemorrhage. A pilot study. Acta Ophthalmol. 1986;64:274-81.

6. Diehl DL, Quigley HA, Miller NR, Sommer A, Burney EN. Prevalence and significance of optic disc hemorrhage in a longitudinal study of glaucoma. Arch Ophthalmol. 1990;108:545-50.

7. Jonas JB, Xu L. Optic disk hemorrhages in glaucoma. Am J Ophthalmol. 1994;118:1-8.

8. Siegner SW, Netland PA. Optic disc hemorrhages and progression of glaucoma. Ophthalmology. 1996;103:1014-24.

9. Sugiyama K, Tomita G, Kitazawa Y, Onda E, Shinohara H, Park $\mathrm{KH}$. The associations of optic disc hemorrhage with retinal nerve fiber layer defect and peripapillary atrophy in normal-tension glaucoma. Ophthalmology. 1997;104:1926-33.

10. Drance SM, Begg IS. Sector haemorrhage--a probable acute ischaemic disc change in chronic simple glaucoma. Can J Ophthalmol. 1970;5:137-41.

11. Klein BE, Klein R, Sponsel WE, Franke T, Cantor LB, Martone J, et al. Prevalence of glaucoma. The Beaver Dam Eye Study. Ophthalmology. 1992;99:1499-504.

12. Wang Y, Xu L, Hu L, Wang Y, Yang H, Jonas JB. Frequency of optic disk hemorrhages in adult chinese in rural and urban china: the Beijing eye study. Am J Ophthalmol. 2006;142:241-6.

13. Healey PR, Mitchell P, Smith W, Wang JJ. Optic disc hemorrhages in a population with and without signs of glaucoma. Ophthalmology. 1998;105:216-23.

14. Tomidokoro A, Iwase A, Araie M, Yamamoto T, Kitazawa Y. Population-based prevalence of optic disc haemorrhages in elderly Japanese. Eye. 2009;23:1032-7.

15. Varma R, Ying-Lai M, Francis BA, Nguyen BB, Deneen J, Wilson MR, et al. Prevalence of open-angle glaucoma and ocular hypertension in Latinos: the Los Angeles Latino Eye Study. Ophthalmology. 2004;111:1439-48.

16. Kitazawa Y, Shirato S, Yamamoto T. Optic disc hemorrhage in low-tension glaucoma. Ophthalmology. 1986;93:853-7.

17. Uhler TA, Piltz-Seymour J. Optic disc hemorrhages in glaucoma and ocular hypertension: implications and recommendations. Curr Opin Ophthalmol. 2008;19:89-94.

18. Ishida K, Yamamoto T, Sugiyama K, Kitazawa Y. Disk hemorrhage is a significantly negative prognostic factor in normaltension glaucoma. Am J Ophthalmol. 2000;129:707-14.

19. Soares AS, Artes PH, Andreou P, Leblanc RP, Chauhan BC, Nicolela MT. Factors associated with optic disc hemorrhages in glaucoma. Ophthalmology. 2004;111:1653-7.

20. Kim YD, Han SB, Park KH, Kim SH, Kim SJ, Seong M, et al. Risk factors associated with optic disc haemorrhage in patients with normal tension glaucoma. Eye. 2010;24:567-72.

21. Jonas JB, Martus P, Budde WM, Hayler J. Morphologic predictive factors for development of optic disc hemorrhages in glaucoma. Invest Ophthalmol Vis Sci. 2002;43:2956-61.

22. Wilde C, Poostchi A, Mehta RL, MacNab HK, Hillman JG, Vernon $\mathrm{SA}$, et al. Prevalence of age-related macular degeneration in an 
elderly UK Caucasian population-The Bridlington Eye Assessment Project: a cross-sectional study. Eye. 2017;10:1042-50.

23. Jonas JB, Budde WM, Panda-Jonas S. Ophthalmoscopic evaluation of the optic nerve head. Surv Ophthalmol. 1999;43:293-320.

24. Jonas JB, Gusek GC, Naumann GO. Optic disc, cup and neuroretinal rim size, configuration and correlations in normal eyes. Invest Ophthalmol Vis Sci. 1988;29:1151-8.

25. Airaksinen PJ. Fellow eyes of glaucomatous patients with uniocular optic disc haemorrhage. Acta Ophthalmol. 1981;59:231-6.

26. Bengtsson B, Leske MC, Hyman L, Heijl A, Early Manifest Glaucoma Trial G. Fluctuation of intraocular pressure and glaucoma progression in the early manifest glaucoma trial. Ophthalmology. 2007;114:205-9.

27. Budenz DL, Anderson DR, Feuer WJ, Beiser JA, Schiffman J, Parrish RK 2nd, et al. Detection and prognostic significance of optic disc hemorrhages during the Ocular Hypertension Treatment Study. Ophthalmology. 2006;113:2137-43.

28. Kim DW, Kim YK, Jeoung JW, Kim DM, Park KH, Epidemiologic Survey Committee of the Korean Ophthalmological S. Prevalence of optic disc hemorrhage in Korea: The Korea National Health and Nutrition Examination Survey. Invest Ophthalmol Vis Sci. 2015;56:3666-72.

29. Park HS, Yoo C, Kim JM, Sung KC, Shim SH, Bae JH, et al. Disc hemorrhages and their risk factors in an urban South Korean population. Optom Vis Sci. 2015;92:700-6.

30. Sugiyama K, Uchida H, Tomita G, Sato Y, Iwase A, Kitazawa Y. Localized wedge-shaped defects of retinal nerve fiber layer and disc hemorrhage in glaucoma. Ophthalmology. 1999;106:1762-7.

31. Yamamoto T, Iwase A, Kawase K, Sawada A, Ishida K. Optic disc hemorrhages detected in a large-scale eye disease screening project. J Glaucoma. 2004;13:356-60.

32. Gloster J. Incidence of optic disc haemorrhages in chronic simple glaucoma and ocular hypertension. Br J Ophthalmol. 1981; 65:452-6

33. Hendrickx KH, van den Enden A, Rasker MT, Hoyng PF. Cumulative incidence of patients with disc hemorrhages in glaucoma and the effect of therapy. Ophthalmology. 1994;101:1165-72.

34. Suh MH, Park KH. Period prevalence and incidence of optic disc haemorrhage in normal tension glaucoma and primary open-angle glaucoma. Clin Exp Ophthalmol. 2011;39:513-9.

35. Zheng Y, Wong TY, Mitchell P, Friedman DS, He M, Aung T. Distribution of ocular perfusion pressure and its relationship with open-angle glaucoma: the singapore malay eye study. Invest Ophthalmol Vis Sci. 2010;51:3399-404.

36. Clarke PM, Walter SJ, Hayen A, Mallon WJ, Heijmans J, Studdert DM. Survival of the fittest: retrospective cohort study of the longevity of Olympic medallists in the modern era. BMJ. 2012;345:e8308.

37. Lane D, Beevers M, Barnes N, Bourne J, John A, Malins S, et al. Inter-arm differences in blood pressure: when are they clinically significant? J Hypertens. 2002;20:1089-95.

38. Pesola GR, Pesola HR, Nelson MJ, Westfal RE. The normal difference in bilateral indirect blood pressure recordings in normotensive individuals. Am J Emerg Med. 2001;19:43-5.

39. Arnold JJ, Sarks SH, Killingsworth MC, Sarks JP. Reticular pseudodrusen. A risk factor in age-related maculopathy. Retina. 1995;15:183-91.

40. Querques G, Querques L, Forte R, Massamba N, Coscas F, Souied EH. Choroidal changes associated with reticular pseudodrusen. Invest Ophthalmol Vis Sci. 2012;53:1258-63.

41. Haas P, Esmaeelpour M, Ansari-Shahrezaei S, Drexler W, Binder S. Choroidal thickness in patients with reticular pseudodrusen using 3D 1060-nm OCT maps. Invest Ophthalmol Vis Sci. 2014;55:2674-81.
42. Lee KM, Lee EJ, Kim TW. Juxtapapillary choroid is thinner in normal-tension glaucoma than in healthy eyes. Acta Ophthalmol. 2016;94:e697-708.

43. Hirooka K, Fujiwara A, Shiragami C, Baba T, Shiraga F. Relationship between progression of visual field damage and choroidal thickness in eyes with normal-tension glaucoma. Clin Exp Ophthalmol. 2012;40:576-82.

44. Roberts KF, Artes PH, O'Leary N, Reis AS, Sharpe GP, Hutchison DM, et al. Peripapillary choroidal thickness in healthy controls and patients with focal, diffuse, and sclerotic glaucomatous optic disc damage. Arch Ophthalmol. 2012;130:980-6.

45. Chung HS, Harris A, Kagemann L, Martin B. Peripapillary retinal blood flow in normal tension glaucoma. $\mathrm{Br} \mathrm{J}$ Ophthalmol. 1999;83:466-9.

46. Sugiyama T, Schwartz B, Takamoto T, Azuma I. Evaluation of the circulation in the retina, peripapillary choroid and optic disk in normal-tension glaucoma. Ophthalmic Res. 2000;32:79-86.

47. Spaide RF. Age-related choroidal atrophy. Am J Ophthalmol. 2009;147:801-10.

48. Boddu S, Lee MD, Marsiglia M, Marmor M, Freund KB, Smith RT. Risk factors associated with reticular pseudodrusen versus large soft drusen. Am J Ophthalmol. 2014;157:985-93.e2.

49. Pumariega NM, Smith RT, Sohrab MA, Letien V, Souied EH. A prospective study of reticular macular disease. Ophthalmology. 2011;118:1619-25.

50. Fleckenstein M, Schmitz-Valckenberg S, Lindner M, Bezatis A, Becker E, Fimmers R, et al. The "diffuse-trickling" fundus autofluorescence phenotype in geographic atrophy. Invest Ophthalmol Vis Sci. 2014;55:2911-20.

51. Corbett JJ, Phelps CD, Eslinger P, Montague PR. The neurologic evaluation of patients with low-tension glaucoma. Invest Ophthalmol Vis Sci. 1985;26:1101-4.

52. Phelps CD, Corbett JJ. Migraine and low-tension glaucoma. A case-control study. Invest Ophthalmol Vis Sci. 1985;26:1105-8.

53. Drance S, Anderson DR, Schulzer M, Collaborative NormalTension Glaucoma Study G. Risk factors for progression of visual field abnormalities in normal-tension glaucoma. Am J Ophthalmol. 2001;131:699-708.

54. Furlanetto RL, De Moraes CG, Teng CC, Liebmann JM, Greenfield DS, Gardiner SK, et al. Risk factors for optic disc hemorrhage in the low-pressure glaucoma treatment study. Am J Ophthalmol. 2014;157:945-52.

55. Park KH, Tomita G, Liou SY, Kitazawa Y. Correlation between peripapillary atrophy and optic nerve damage in normal-tension glaucoma. Ophthalmology. 1996;103:1899-906.

56. Sugiyama K, Tomita G, Kawase K, Onda E, Shinohara H, Hayakawa T, et al. Disc hemorrhage and peripapillary atrophy in apparently healthy subjects. Acta Ophthalmol Scand. 1999;77:139-42.

57. Garg A, Blumberg DM, Al-Aswad LA, Oll M, Yzer S, Forbes M, et al. Associations between beta-peripapillary atrophy and reticular pseudodrusen in early age-related macular degeneration. Invest Ophthalmol Vis Sci. 2017;58:2810-5.

58. Klein R, Meuer SM, Knudtson MD, Iyengar SK, Klein BE. The epidemiology of retinal reticular drusen. Am J Ophthalmol. 2008;145:317-26.

59. Skalicky SE, Fenwick E, Martin KR, Crowston J, Goldberg I, McCluskey P. Impact of age-related macular degeneration in patients with glaucoma: understanding the patients' perspective. Clin Exp Ophthalmol. 2016;44:377-87.

60. Ramulu P. Glaucoma and disability: which tasks are affected, and at what stage of disease? Curr Opin Ophthalmol. 2009;20:92-8.

61. Cahill MT, Banks AD, Stinnett SS, Toth CA. Vision-related quality of life in patients with bilateral severe age-related macular degeneration. Ophthalmology. 2005;112:152-8. 